\title{
Analisis Triple Exponential Smoothing untuk Peramalan Kredit yang Diberikan Bank Umum Konvensional dan Syariah
}

\author{
Astri Afrilia \\ UIN Sunan Gunung Djati Bandung, Bandung \\ E-mail : astriafrilia88@gmail.com
}

\begin{abstract}
Credit provided by banks is an important financial item that needs to be predicted in amount. This is because the main income of most banks in Indonesia still comes from credit. One of the analytical techniques that can be used is the triple exponential smoothing method. This study aims to obtain the results of the prediction of loans given in the future period for conventional and sharia commercial banks. From the results of data processing, it was found that the alpha value of 0.3 gave a forecast result of IDR $8,195,603$ billion with the highest accuracy or the smallest error based on the MAD and MAPE values, which were IDR 59,199 billion and $0.78 \%$. Thus, it can be said that the Triple Exponential Smoothing method is an effective and efficient method to predict the amount of credit provided by conventional and sharia commercial banks.
\end{abstract}

Keywords : Credit Provided, Triple Exponential Smoothing, MAD, MAPE.

\begin{abstract}
Abstrak
Kredit yang diberikan bank merupakan pos keuangan penting yang perlu diprediksikan jumlahnya. Hal ini dikarenakan pendapatan utama sebagian besar bank di Indonesia masih bersumber dari kredit. Salah satu teknik analisis yang dapat digunakan adalah metode triple exponential smoothing. Penelitian ini bertujuan untuk memperoleh hasil ramalan (prediksi) kredit yang diberikan pada periode mendatang bagi Bank Umum Konvensional dan Syariah. Dari hasil pengolahan data diperoleh bahwa nilai alpha sebesar 0,3 memberikan hasil ramalan sebesar Rp 8.195.603 miliar dengan akurasi tertinggi atau error terkecil berdasarkan nilai MAD dan MAPE yakni sebesar Rp 59.199 Miliar dan 0.78\%. Sehingga, dapat dikatakan bahwa metode Triple Exponential Smoothing merupakan metode yang efektif dan efisien untuk meramalkan jumlah KYD Bank Umum Konvensional dan Syariah.
\end{abstract}

Kata kunci : Kredit yang Diberikan, Triple Exponential Smoothing, MAD, MAPE. 


\section{PENDAHULUAN}

Kredit bagi sebagian besar perbankan masih menjadi sumber utama pendapatan bank. Andrianto, (2020) memaparkan bahwa penyaluran kredit masih memberikan kontribusi tertinggi laba sebuah bank. Semakin besar aktivitas pembangunan serta semakin tinggi pertumbuhan ekonomi suatu negara, semakin besar pula peranan yang dilakukan oleh bank, baik dari segi pengerahan dana maupun dari segi arah dan volume kredit yang diberikan/disalurkan. Pertumbuhan kredit dapat mengindikasikan majunya perekonomian suatu negara. Sipahutar, dkk (2020) memaparkan bahwa pada perekonomian nasional, kredit yang diberikan oleh bank-bank di Indonesia merupakan growth accelerating factor melalui sektor riil sebagai transmission channel. Terdapat hubungan kausalitas antara kredit perbankan dengan pertumbuhan ekonomi nasional, yaitu pertumbuhan ekonomi dipengaruhi kredit perbankan dan sebaliknya, credit depth dipengaruhi pertumbuhan ekonomi. Besar kontribusi kredit perbankan pada pertumbuhan ekonomi negara adalah 6.5\%. Pada pertumbuhan ekonomi Indonesia, kredit menjadi sumber pemicu percepatan. Lebih lanjut, pengangguran dan kemiskinan dapat direduksi oleh kredit perbankan.

Peran kredit yang begitu penting perlu diprediksikan agar bank dapat mempersiapkan sejumlah skenario pos keuangan lainnya untuk meningkatkan kinerjanya. Selain itu, prediksi pertumbuhan kredit dibutuhkan bank dalam menyusun Rencana Bisnis Bank (RBB) yang digunakan bank untuk menentukan standar kinerja yang harus dicapai melalui pengawasan yang dilakukan. Prediksi pertumbuhan kredit tersebut dapat dilakukan dengan menggunakan metode statistik time series analysis, salah satunya Triple Exponential Smoothing Method. Noreen, et al. (2017) melakukan penelitian untuk memprediksi penyaluran kredit bank, namun menggunakan metode ARIMA. Marlianah, dkk (2019) melakukan penelitian untuk meramalkan kredit Pemerintah Indonesia dari luar negeri, namun metode statistik yang digunakan adalah double exponential smooting method. Chui, et al (2014) melakukan prediksi arus kas bank menggunakan metode time series exponential smoothing namun masih pemulusan tingkat pertama dan kedua. Erkekoglu, et al (2020) juga menggunakan metode exponential smoothing untuk memprediksi variabel makroekonomi, namun metode yang digunakan masih pemulusan tingkat pertama dan kemudian dibandingkan hasilnya dengan ARIMA dan VAR. Dengan demikian, kebaruan dari penelitian ini adalah menggunakan metode exponential smoothing dengan pemulusan 1 (satu) tingkat yang lebih tinggi, yakni pemulusan ketiga, dan digunakan untuk memprediksi pertumbuhan kredit perbankan di Indonesia (konvensional dan syariah) yang belum dilakukan oleh peneliti-peneliti terdahulu. Adapun tujuan penelitian ini adalah untuk memperoleh nilai ramalan (prediksi) jumlah Kredit Yang Diberikan (KYD) Bank Umum Konvensional dan Syariah pada periode selanjutnya.

\section{METODOLOGI}

\section{Data Penelitian}

Dataset yang digunakan bersumber dari website Otoritas Jasa Keuangan (OJK) yang disediakan secara periodik per akhir tahun selama tahun 2017 sampai tahun 2021 (data bulanan). Data tersebut mencakup data penyaluran kredit Bank Umum Konvensional juga Syariah. Tidak ada missing value dalam dataset ini, sehingga data penelitian berjumlah 54 pengamatan penyaluran kredit dari posisi Januari 2017 sampai dengan Juni 2021.

\section{Metode Penelitian}

\section{Metode Exponential Smoothing}

Makridakis dalam Raihan, dkk (2016) mendefinisikan metode exponential smoothing merupakan prosedur perbaikan terus menerus pada peramalan terhadap objek pengamatan terbaru. Penitikberatan metode ini yaitu penurunan utama secara eksponensial pada data sebelumnya. Metode ini biasa digunakan ketika data menunjukkan adanya trend. Metode ini membutuhkan suatu level pemulusan. 
Margaret\&Jose (2015) memaparkan bahwa exponential smoothing dapat diterapkan pada data deret waktu, dapat untuk menghasilkan data persentase pemulusan atau membuat peramalan. Jenis-jenis exponential smoothing adalah pemulusan tingkat pertama (single), ganda (double) dan tripel (triple).

\section{Triple Exponential Smoothing}

Metode triple exponential smoothing merupakan pengembangan dari metode pemulusan tingkat pertama dan kedua. Metode ini cocok untuk data deret waktu yang menunjukkan adanya trend atau perilaku musiman. Metode ini memiliki kelebihan untuk menghasilkan nilai ramalan yang lebih baik, karena dalam proses analisisnya dilakukan 3 (tiga) kali pemulusan dengan nilai alpha yang disesuaikan peneliti (Subagyo, 2013). Berikut adalah model matematis untuk pemulusan triple exponential smoothing brown.

1. Pemulusan Tunggal :

$$
S_{t}^{\prime}=\alpha X_{t}+(1-\alpha) S_{t-1}^{\prime}
$$

2. Pemulusan Ganda

$$
S_{t}^{\prime}=\alpha X_{t}+(1-\alpha) S_{t-1}^{\prime}
$$

3. Pemulusan Tripel :

$$
S^{\prime \prime \prime}{ }_{t}=\alpha S_{t}^{\prime \prime}+(1-\alpha) S^{\prime^{\prime \prime}}
$$

4. Pemulusan Total

$$
a_{t}=3 S_{t}^{\prime}-3 S_{t}^{\prime \prime}+S_{t}^{\prime \prime}
$$

5. Pemulusan Tren:

$$
b_{t}=\frac{\alpha}{2(1-\alpha)^{2}}\left[(6-5 \alpha) S_{t}^{\prime}-(10-8 \alpha) S_{t}^{\prime \prime}+(4-3 \alpha) S^{\prime \prime \prime}{ }_{t}\right]
$$

6. Pemulusan Kuadratik :

7. Peramalan

$$
c_{t}=\frac{\alpha^{2}}{(1-\alpha)^{2}}\left(S_{t}^{\prime}-2 S_{t}^{\prime \prime}+S_{t}^{\prime \prime \prime}\right)
$$

dimana,

$$
F_{t+m}=a_{t}+b_{t} m+\frac{1}{2} c_{t} m^{2}
$$

$S_{t}^{\prime}$ adalah nilai pemulusan tingkat pertama (single)

$S^{\prime \prime}$, adalah nlai pemulusan tingkat kedua (double)

$S^{\prime \prime \prime}$ adalah nilai pemulusan tingkat ketiga (triple)

$X_{t}$ adalah nilai pemulusan tunggal

$a_{t}$ adalah pemulusan total

$b_{t}$ adalah pemulusan tren

$c_{t}$ adalah pemulusan kuadratik

$F_{t+m}$ adalah nilai ramalan

$m$ adalah periode masa mendatang

$\alpha$ adalah konstanta pemulusan dengan nilai antara 0 dan 1 


\section{Perhitungan Akurasi Ramalan}

Agar dapat mengetahui kinerja metode ramalan yang digunakan, maka penulis menggunakan perhitungan MAD (Mean Absolute Deviation) dan MAPE (Mean Absolute Percentage Error).

Mean Absolute Deviation (MAD) mengukur akurasi ramalan dengan mencari rata-rata dari nilai mutlak masing-masing kesalahan. MAD efektif apabila pengguna ingin mengukur kesalahan ramalan dalam unit yang sama dengan deret asli. Montgomery, et al (2015) MAD dapat dihitung dengan rumus sebagai berikut.

$$
M A D=\frac{1}{n} \sum_{t=1}^{n}\left|X_{t}-F_{t}\right|
$$

Mean Absolute Percentage Error (MAPE) dihitung dengan menggunakan kesalahan absolut pada tiap waktu dibagi dengan nilai observasi riil itu sendiri. Kemudian, dicari rata-ratanya. Pendekatan ini efektif digunakan ketika ukuran atau besar variabel ramalan itu penting dalam mengevaluasi ketepatan ramalan. Stephano, A (2020) memaparkan bahwa MAPE dapat dihitung dengan rumus sebagai berikut.

$$
M A P E=\frac{1}{n} \sum_{t=1}^{n} \frac{\left|X_{t}-F_{t}\right|}{X_{t}} * 100
$$

\section{HASIL DAN PEMBAHASAN}

Pengolahan data untuk mendapatkan hasil ramalan menggunakan aplikasi POM for Windows. Kemudian, dipilih nilai statistik alpha $(\alpha)$ bervariasi yakni sebesar $0.1 ; 0.3$; dan 0.5 untuk kemudian dibandingkan hasil akurasi ramalannya. Langkah peramalan dilakukan dengan memperoleh hasil ramalan pemulusan tingkat pertama yang akan menjadi input pada proses pemulusan tingkat kedua (ganda) juga demikian hasil tersebut akan menjadi input untuk pemulusan tingkat ketiga. Tabel 2 berikut memuat hasil ramalan dengan tingkat alpha 0.1 .

TABEL 2. Hasil Ramalan dengan Tingkat Alpha 0.1

\begin{tabular}{cccccccccc}
\hline \multirow{2}{*}{ Tahun } & \multirow{2}{*}{ Bulan } & $\begin{array}{c}\text { KYD } \\
\text { (Miliar Rp) }\end{array}$ & $S_{t}^{\prime}$ & $S_{t}^{\prime \prime}$ & $S_{t}^{\prime \prime}$ & $a_{t}$ & $b_{t}$ & $c_{t}$ & Ramalan \\
\hline \multirow{2}{*}{2017} & Januari & 5.797 .196 & 5.797 .197 & 5.797 .197 & 5.797 .197 & 5.797 .197 & - & - & \\
& Februari & 5.824 .582 & 5.799 .936 & 5.797 .471 & 5.797 .224 & 5.804 .618 & 780 & 27 & \\
& Maret & 5.905 .787 & 5.810 .521 & 5.798 .776 & 5.797 .380 & 5.832 .614 & 3.669 & 128 & 5.805 .412 \\
& April & 5.938 .353 & 5.823 .304 & 5.801 .229 & 5.797 .765 & 5.863 .991 & 6.704 & 230 & 5.836 .346 \\
& Mei & 5.969 .415 & 5.837 .915 & 5.804 .897 & 5.798 .478 & 5.897 .531 & 9.744 & 328 & 5.870 .809 \\
& Juni & 6.000 .596 & 5.854 .183 & 5.809 .826 & 5.799 .613 & 5.932 .684 & 12.727 & 422 & 5.907 .439 \\
& Juli & 6.032 .899 & 5.872 .055 & 5.816 .049 & 5.801 .256 & 5.969 .274 & 15.636 & 509 & 5.945 .622 \\
& Agustus & 6.032 .899 & 5.888 .139 & 5.823 .258 & 5.803 .456 & 5.998 .100 & 17.505 & 557 & 5.985 .164 \\
& September & 6.210 .484 & 5.920 .374 & 5.832 .970 & 5.806 .408 & 6.068 .620 & 23.608 & 751 & 6.015 .884 \\
& Oktober & 6.248 .902 & 5.953 .227 & 5.844 .995 & 5.810 .267 & 6.134 .960 & 28.813 & 907 & 6.092 .604 \\
& November & 6.281 .442 & 5.986 .048 & 5.859 .101 & 5.815 .150 & 6.195 .993 & 33.061 & 1.025 & 6.164 .228 \\
& Desember & 6.377 .940 & 6.025 .237 & 5.875 .714 & 5.821 .207 & 6.269 .776 & 38.315 & 1.173 & 6.229 .566 \\
\hline \multirow{2}{*}{2018} & Januari & 6.347 .428 & 6.057 .456 & 5.893 .889 & 5.828 .475 & 6.319 .178 & 40.592 & 1.212 & 6.308 .677 \\
& Februari & 6.460 .366 & 6.097 .747 & 5.914 .275 & 5.837 .055 & 6.387 .473 & 44.654 & 1.312 & 6.360 .376 \\
& Maret & 6.550 .441 & 6.143 .017 & 5.937 .149 & 5.847 .064 & 6.464 .668 & 49.319 & 1.429 & 6.432 .783 \\
& April & 6.540 .053 & 6.182 .720 & 5.961 .706 & 5.858 .528 & 6.521 .571 & 51.470 & 1.455 & 6.514 .701 \\
\hline
\end{tabular}




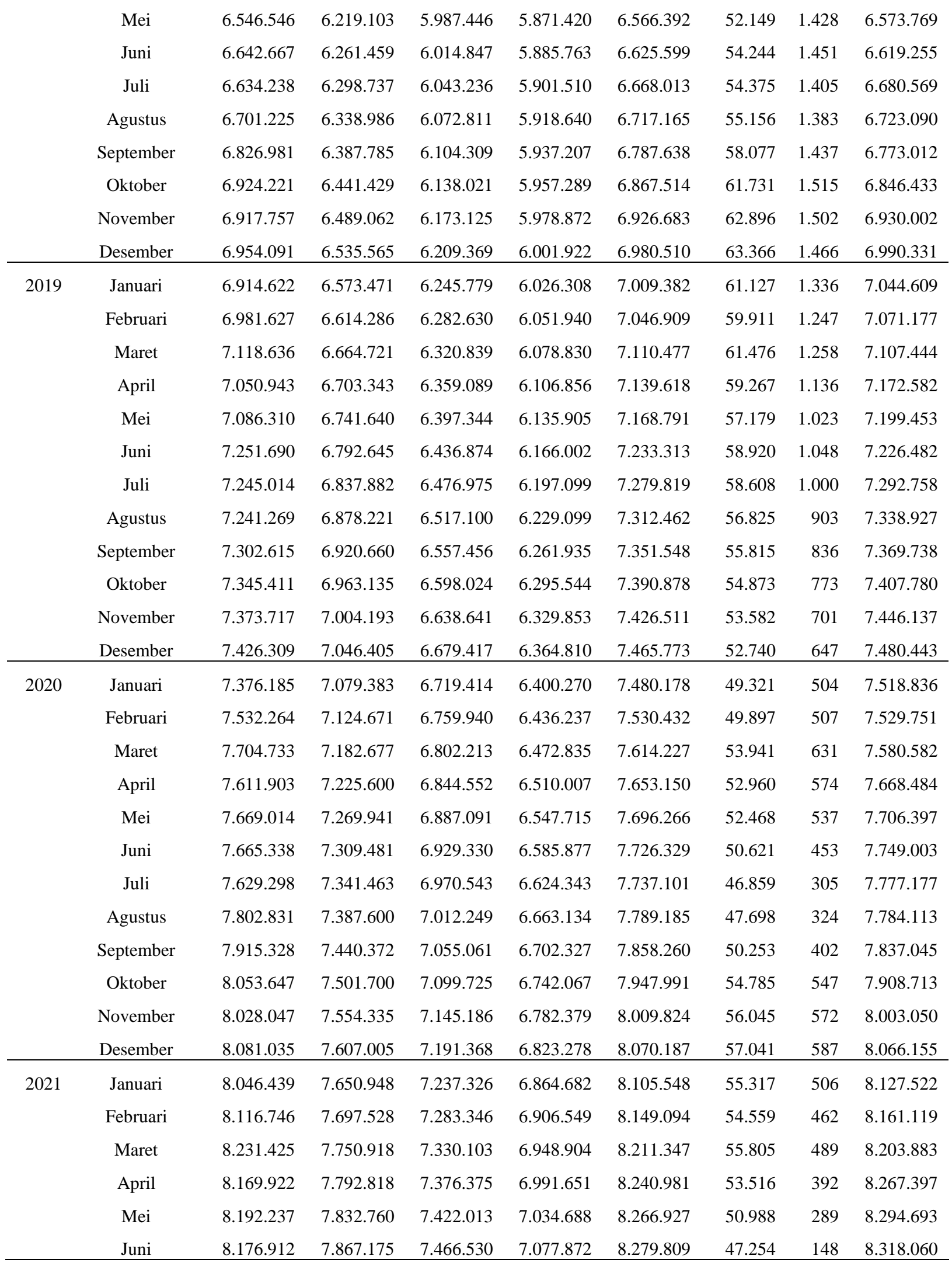

Berdasarkan TABEL 2 dapat diperoleh data ramalan untuk periode selanjutnya yakni Juli 2022 sebagai berikut. 


$$
\begin{aligned}
& F_{t+m}=a_{t}+b_{t} m+\frac{1}{2} c_{t} m^{2} \\
& F_{t}=8.279 .809+47.254(1)+\frac{1}{2}(148)\left(1^{2}\right) \\
& F_{t}=8.327 .137
\end{aligned}
$$

$F_{t}$ adalah nilai ramalan pada periode yang akan datang. Dengan demikian, dapat diketahui nilai ramalan untuk periode selanjutnya (Juli 2021) adalah sebesar Rp. 8.327.137 Miliar. Setelah diperoleh nilai ramalan, maka dapat dicari nilai MAD, MSE dan MAPE untuk setiap alpha dengan proses perhitungan yang sama. Hasil ramalan serta perhitungan hasil akurasi ramalan dimuat dalam TABEL 3.

TABEL 3. Hasil Ramalan untuk Berbagai Tingkat Alpha

\begin{tabular}{cccc}
\hline Alpha & $\begin{array}{c}\text { Ramalan } \\
\text { (Miliar Rp) }\end{array}$ & MAD & MAPE \\
\hline 0.1 & 8.327 .137 & 73876.76 & $1.06 \%$ \\
0.3 & 8.195 .603 & 55524.16 & $0.78 \%$ \\
0.5 & 8.177 .368 & 59199.91 & $0.83 \%$ \\
\hline
\end{tabular}

Berdasarkan hasil perhitungan akurasi ramalan dalam TABEL 3, dapat diketahui bahwa nilai alpha sebesar 0.3 memberikan nilai MAD terkecil yakni sebesar Rp 55.199 Miliar dan MAPE terkecil yakni sebesar $0.78 \%$. Sementara, nilai error terbesar diberikan oleh tingkat alpha sebesar 0.1. Dengan demikian, untuk dapat membandingkan tingkat alpha yang memberikan error terkecil, maka pengguna metode peramalan ini harus mencoba beberapa tingkat alpha. Telah dimuat dalam Tabel 2 bahwa nilai ramalan yang diberikan untuk posisi Juli 2021 adalah sebesar Rp 8.195.603 miliar. Agar dapat memberikan gambaran perbandingan antara data riil dan data ramalan, maka dilakukan plotting data riil dan hasil ramalan untuk setiap nilai alpha yang dimuat dalam grafik sebagaimana GAMBAR 1, 2 dan 3 berikut.

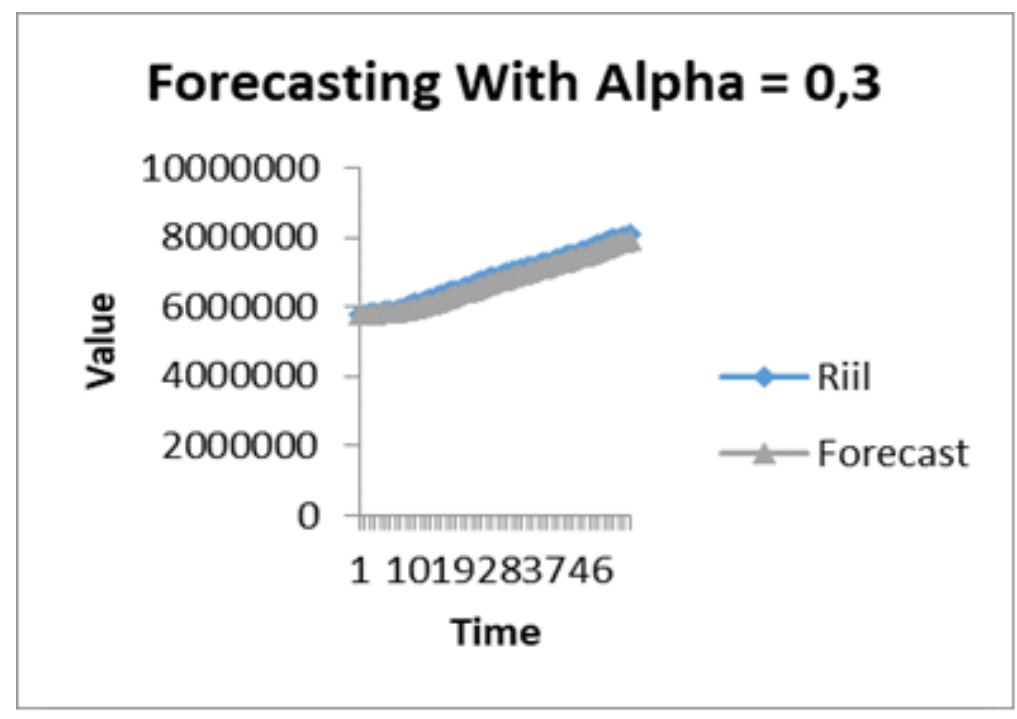

GAMBAR 1. Grafik Data Riil dan Hasil Ramalan pada Tingkat Alpha $=0.3$ 


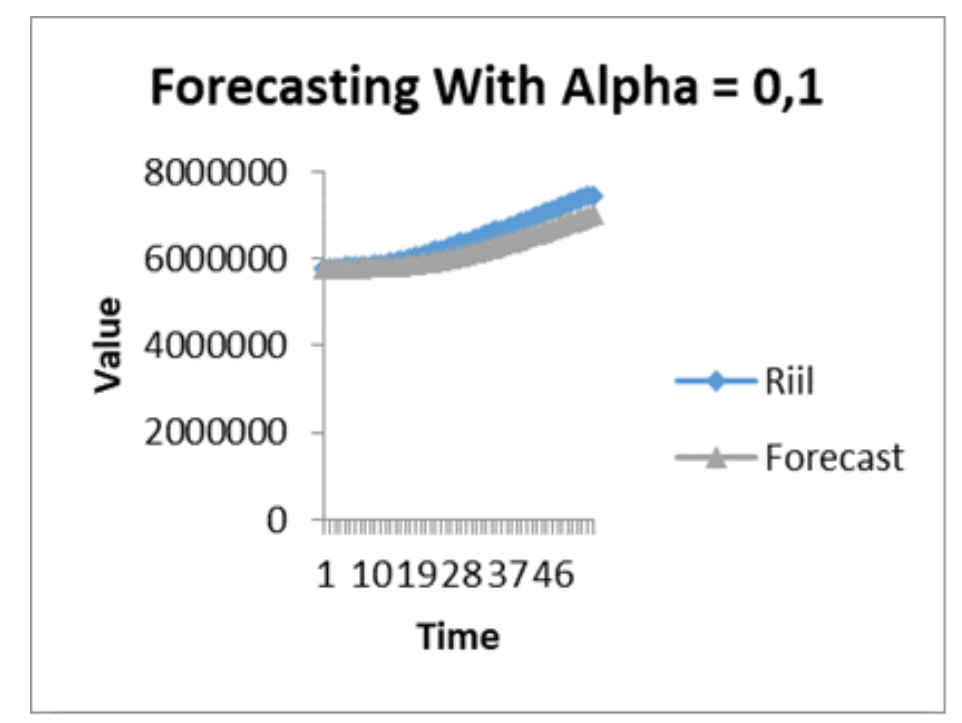

GAMBAR 2. Grafik Data Riil dan Hasil Ramalan pada Tingkat Alpha $=0.1$

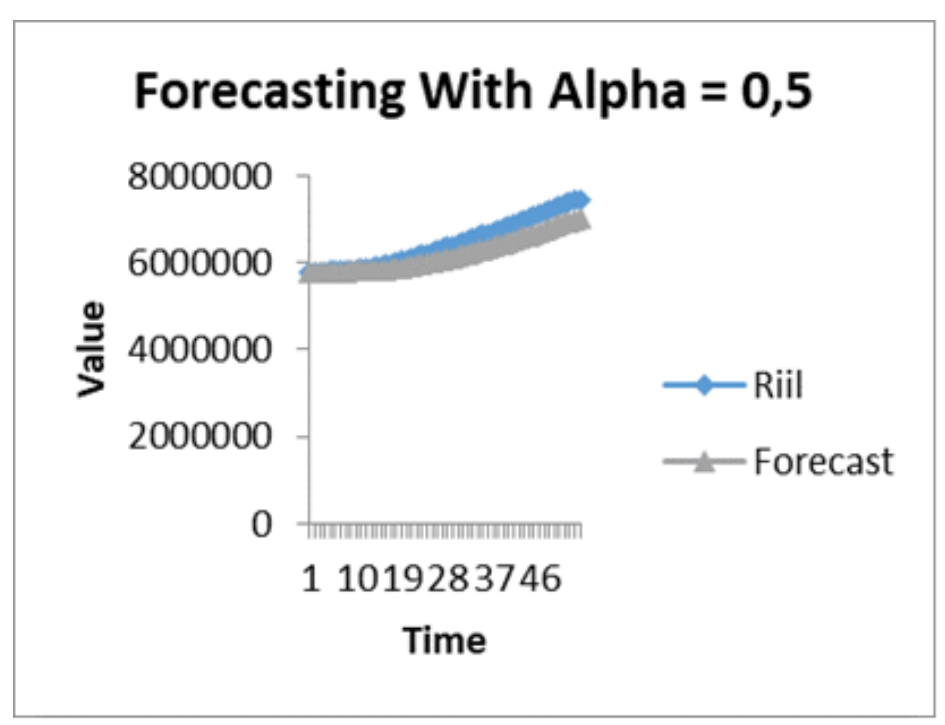

GAMBAR 3. Grafik Data Riil dan Hasil Ramalan pada Tingkat Alpha $=0.5$

Berdasarkan GAMBAR 1, (alpha $=0.3)$ terlihat bahwa pola hasil ramalan mengikuti pola data riil dan hanya berjarak sedikit yang terlihat dari pola garis forecast dibandingkan GAMBAR 2 (alpha= 0.1 ) dan GAMBAR 3 (alpha = 0.5). Hal ini menandakan galat (error) yang relatif kecil karena gap antar plot relatif kecil (berhimpitan).

Hasil penelitian ini memberikan tingkat error yang lebih kecil dibandingkan hasil pada penelitian terdahulu yang dilakukan oleh Marlianah, dkk (2019) dimana nilai MAPE yang diperoleh adalah sebesar 1.37\%, juga Chui, et al. (2014) sebesar 1.10\%, serta Erkekoglu, et al. (2020) sebesar $28.11 \%$.

\section{KESIMPULAN}

Berdasarkan hasil pengolahan data yang dilakukan peneliti menggunakan metode Triple Exponential Smoothing, diketahui bahwa nilai alpha sebesar 0.3 memberikan tingkat akurasi yang terbaik, yakni yang memiliki tingkat error terkecil berdasarkan nilai MAD dan MAPE. Nilai MAD untuk alpha sebesar 0.3 yakni sebesar Rp 59.199 Miliar dan MAPE sebesar 0.78\%. Adapun nilai ramalan yang diberikan untuk posisi Juli 2021 adalah sebesar Rp 8.195.603 miliar. Sehingga, dapat 
dikatakan bahwa metode Triple Exponential Smoothing merupakan metode yang efektif dan efisien untuk meramalkan jumlah KYD Bank Umum Konvensional dan Syariah.

\section{REFERENSI}

Andrianto. 2020, 'Manajemen Kredit : Teori dan Konsep Bagi Bank Umum'. Pasuruan : CV. Qiara Media.

Chui, W.H., Wang, J.S., \& Ning, C.X. 2014, 'Time Series Prediction Method of Bank Cash Flow and Simulation Comparison', Algorithms Journal, vol. 7, hh. 650-662.

Erkekoglu, H., Garang, A.P.M., \& Deng, A.S. 2020, 'Comparative Evaluation of Forecast Accuracies for ARIMA, Exponential Smoothing and VAR', International Journal of Economics and Financial Issues, vol. 10, no. 6, hh. 206-216.

Fitria, V., \& Anwar, S. 2020, 'Penerapan Triple Exponential Smoothing dalam Meramalkan Laju Inflasi Bulanan Provinsi Aceh', E-Jurnal Ekonomi dan Bisnis Universitas Udayana, vol. 9, no. 1, hh. 23-38.

Margaret, V., \& Jose, J. 2015, 'Exponential Smoothing Models for Prediction of Solar Irradiance', International Journal of Advanced Research in Electrical, Electronics and Instrumentation Evolusi: Engineering, vol. 4, no. 2, hh.1133-1139

Marlianah, S., Meilani, C., Lina, Q., \& Widodo, E. 2019, 'Analisis Double Exponential Smoothing Untuk Meramalkan Utang Pemerintah Indonesia ke Luar Negeri', Prosiding Seminar Nasional MIPA UNIBA.

Mokhtar, S., \& Syamsu, N. 2020, 'Optimalisasi Strategi Pemasaran Dana Pihak Ketiga Melalui Pendekatan Teknik Peramalan Exponential Smoothing di Bank Syariah Mandiri', Jurnal Ekonomi Pembangunan, vol. 6, no. 2, hh. 128-144.

Montgomery, D.C., Jenning, C., \& Kulahci, M. 2015, 'Introduction to Time Series Analysis and Forecasting'. Canada : John Wiley and Sons Inc.

Noreen, A., Asif, R., Nisar, S., \& Qayyum, N. 2017, 'Model Building and Forecasting of Bank Credit to Public and Private Sector', Universal Journal of Accounting and Finance, vol. 5, no. 4, hh. 7377.

Raihan, Eff, M.S., \& Hendrawan, A. 2016, 'Forecasting Model Exsponensial Smoothing Time Series Rata Rata Mechanical Availability Unit Off Highway Truck Cat 777d Caterpillar', Jurnal Poros Teknik, vol.8, no. 1, hh. 1-54.

Subagyo, P. 2013, 'Forecasting Konsep dan Aplikasi (Ketiga)'. Yogyakarta : BPFE.

Sipahutar, M.A. 2016, 'Keterkaitan Kredit dan Kelembagaan Perbankan Indonesia pada Perekonomian Nasional dan Regional'. Disertasi. Bogor : Institut Pertanian Bogor.

Stephano, A. 2020, ‘Analisis Kuantitatif Untuk Pengambilan Keputusan’. Jakarta : Grasindo. 